\title{
Natural quorum sensing inhibitors effectively downregulate gene expression of Pseudomonas aeruginosa virulence factors
}

\author{
Syed A. K. S. Ahmed ${ }^{1} \cdot$ Michelle Rudden $^{2} \cdot$ Thomas J. Smyth $^{3} \cdot$ James S. G. Dooley $^{1}$ (D) Roger Marchant $^{1}$ \\ Ibrahim M. Banat ${ }^{1}$
}

Received: 12 October 2018 / Revised: 2 January 2019 / Accepted: 4 January 2019 / Published online: 9 March 2019

(C) The Author(s) 2019

\begin{abstract}
At present, anti-virulence drugs are being considered as potential therapeutic alternatives and/or adjuvants to currently failing antibiotics. These drugs do not kill bacteria but inhibit virulence factors essential for establishing infection and pathogenesis through targeting non-essential metabolic pathways reducing the selective pressure to develop resistance. We investigated the effect of naturally isolated plant compounds on the repression of the quorum sensing (QS) system which is linked to virulence/pathogenicity in Pseudomonas aeruginosa. Our results show that trans-cinnamaldehyde (CA) and salicylic acid (SA) significantly inhibit expression of QS regulatory and virulence genes in P. aeruginosa PAO1 at sub-inhibitory levels without any bactericidal effect. CA effectively downregulated both the las and $r h l$ QS systems with lasI and lasR levels inhibited by 13- and 7-fold respectively compared to 3-and 2fold reductions with SA treatment, during the stationary growth phase. The QS inhibitors (QSI) also reduced the production of extracellular virulence factors with CA reducing protease, elastase and pyocyanin by $65 \%, 22 \%$ and $32 \%$, respectively. The QSIs significantly reduced biofilm formation and concomitantly with repressed rhamnolipid gene expression, only trace amount of extracellular rhamnolipids were detected. The QSIs did not completely inhibit virulence factor expression and production but their administration significantly lowered the virulence phenotypes at both the transcriptional and extracellular levels. This study shows the significant inhibitory effect of natural plant-derived compounds on the repression of QS systems in P. aeruginosa.
\end{abstract}

Keywords Trans-cinnamaldehyde $\cdot$ Salicylic acid $\cdot$ Quorum sensing $\cdot$ Quorum sensing inhibitor $\cdot$ Pseudomonas aeruginosa

\section{Introduction}

A review commissioned by the UK government in 2014 (https://amr-review.org/) predicted that there will be more deaths in the world due to antimicrobial resistance (AMR) than cancer by the year 2050. Antibiotic usage creates an evolutionary stress response in the bacterial population that over time leads to the emergence of resistant strains. Extensive use of antibiotics coupled with the diminished pipeline of new antibiotics has seen a rapid evolution of resistance

James S. G. Dooley

jsg.dooley@ulster.ac.uk

1 School of Biomedical Sciences, Ulster University, Coleraine BT52 1SA, UK

2 Department of Biology, University of York, Wentworth, York YO10 5DD, UK

3 School of Science, Institute of Technology Sligo, Sligo, Ireland that has culminated in the development of multi-drug-resistant pathogens that are extremely difficult to treat.

Pseudomonas aeruginosa, a Gram-negative opportunistic pathogen, is prevalent in immunocompromised patients suffering from cystic fibrosis (CF) and human immunodeficiency virus (HIV). These bacteria are notorious biofilm producers. The biofilm provides a stratified environment with the core being more anoxic with low bacterial growth and metabolic rates. These metabolically inactive biofilm cells are resistant to $\beta$-lactam antibiotics (Anwar and Costerton 1990; Werner et al. 2004) ciprofloxacin, tetracycline and tobramycin (Brown et al. 1988). The biofilm layer also acts as a diffusion barrier reducing the rate of antibiotic penetration, preventing sufficient accumulation of antibiotics and allowing time for expression of resistance genes (Jefferson et al. 2005). In CF, $P$. aeruginosa forms biofilms and readily adapts to the lung environment eventually leading to prolonged inflammation and chronic lung infections that are very difficult to treat using conventional antibiotic methods. In addition, the presence of inducible (MexXY) and constitutive (MexAB-OprM) efflux pumps and the poor permeability of the outer membrane also 
contribute to the reduced susceptibility of $P$. aeruginosa to a broad range of antibiotics (Aghazadeh et al. 2014, LópezCausapé et al. 2017). Effective treatment of $P$. aeruginosa is therefore becoming increasingly challenging with the bacterium showing resistance to even the third and the fourth generations of carbapenems and cephalosporins (Luna et al. 2013; Patel et al. 2014). Therefore, it has become critical to find alternative therapies to successfully clear $P$. aeruginosa infections.

$P$. aeruginosa produces a variety of virulence factors, in a coordinated system, that are reported to enable host colonisation and adaptation (Valderrey et al. 2010; Gellatly and Hancock 2013; Sousa and Pereira 2014). These virulence factors include the production of biofilm, pyocyanin, elastase and rhamnolipid and are under the control of a cell density-dependent signalling regulation known as quorum sensing (QS) (Stover et al. 2000; Lee and Zhang 2014; Sousa and Pereira 2014) The canonical QS system in $P$. aeruginosa includes the las and the $r h l$ systems both consisting of LuxI type synthases (LasI and RhlI) which produce specific acyl homoserine lactone (AHL) molecules, N-(3oxododecanoyl)-L-homoserine lactone (3-oxo- $\mathrm{C}_{12}$-HSL) and N-butanoyl-L-homoserine lactone $\left(\mathrm{C}_{4}-\mathrm{HSL}\right)$. At sufficiently high bacterial concentrations, these AHL molecules then bind to the LuxR type receptors (LasR and RhlR) to form transcriptional activation complexes which regulate the transcription of various genes involved with virulence of $P$. aeruginosa (Papenfort and Bassler 2016).

Interfering with this QS system through application of QS inhibitors (QSI) is a novel therapeutic target that has shown to effectively reduce virulence in opportunistic pathogens. The disruption of QS communication can be achieved through the enzymatic degradation of AHL molecules by lactonases, acylases and oxidoreductases or by using small structural molecules that inhibit the QS signal molecule from binding to its cognate regulatory protein (Morohoshi et al. 2009; Kalia 2013; Kisch et al. 2014; Gupta et al. 2015). A synthetic derivative of a furanone, compound $\mathrm{C} 30(\mathrm{C} 30 \mathrm{~F})$, has been shown to supress bacterial $\mathrm{QS}$ in mice lung models through interference with AHL production (Wu et al. 2004) and through attenuation of QS-regulated production of virulence factors (Hentzer et al. 2003). In the recent past, a range of plant compounds have shown to be effective as anti-QS and anti-biofilm agents (Musthafa et al. 2010; Jayelakshmi et al. 2016; Ouyang et al. 2016; Luo et al. 2017). Kim et al. (2015), using an in silico approach, predicted that natural gingerol could bind to the QS regulator LasR protein. They then demonstrated, using standard assays, a decrease in production of several virulence factors and biofilm formation following exposure to gingerol, consistent with interference of the binding of the cognate signal molecule, 3 -oxo- $\mathrm{C}_{12}$-HSL, to LasR. Moreover, access to crystal structure of LasI (Gould et al. 2004) and LasR (Bottomley et al. 2007) along with the availability of computer-aided programs like structure-based virtual screening (SB-VS) and molecular docking have been useful in identifying more compounds with potential anti-QS abilities.
A SB-VS experiment unlocked six drugs with LasR structural similarity including salicylic acid (SA), nifuroxazide and chlorzoxazone (Yang et al. 2009). These compounds were able to significantly inhibit QS gene expression and phenotypes in P. aeruginosa. In another study, molecular docking results showed that a plant compound, trans-cinnamaldehyde (CA), was able to interact with the LasI substrate binding sites by forming hydrophobic and $\pi-\pi$ bonds with phenylalanine27 and 105, tryptophan-33 and a hydrogen bond with arginine-30 in the LasI synthase (Chang et al. 2014). Since QS is related to several virulence mechanisms in $P$. aeruginosa, therefore the ability of compounds like SA and CA to interfere with the QS system can open the possibility of utilising these as effective anti-QS agents for controlling the pathogenic phenotypes of $P$. aeruginosa.

The QS system allows bacteria to adapt to changing environmental conditions at the population level, with the adaptation mediated at the transcriptional level via regulated expression of the QS genes in response to metabolic and environmental stimuli (Wagner et al. 2003; Scott and Hwa 2011). Understanding the transcriptional expression of the QS genes is therefore essential for understanding the physiology of the cell under QS inhibitory conditions. The current information on the ability of CA and SA to reduce QS activity in P. aeruginosa is very limited and has been mostly acquired through crude estimations of virulence proteins or by using high throughput microarray analysis for identifying changes to gene expression (Prithiviraj et al. 2005; Yang et al. 2009). Therefore, in this study, we have used a very robust and MIQE (minimum information for publication of quantitative real-time PCR experiments) compliant reverse transcription quantitative PCR (RTqPCR) assay, a gold standard for low-medium throughput quantitative expression analysis, to study the changes in transcriptomic profiles when $P$. aeruginosa is subjected to CA and SA treatments at sub-inhibitory concentrations. To correlate the effects of the gene expression on the phenotypic profiles following QSI treatment, the QS-regulated virulence factors rhamnolipid, elastase, protease and pyocyanin were estimated.

\section{Materials and methods}

\section{Bacterial strains and media}

The fully sequenced and widely reported laboratory strain P. aeruginosa PAO1 (ATCC 15692) was used in the study. Overnight cultures were prepared from $-80{ }^{\circ} \mathrm{C}$ frozen culture stocks in a nutrient-rich LB broth at $37{ }^{\circ} \mathrm{C}$ under shaking conditions at $180 \mathrm{rpm}$. This culture was subsequently used to inoculate proteose-peptone-glucose-ammonium-salts (PPGAS) medium (Zhang and Miller 1992). The bacteria were cultivated in PPGAS medium at $1 / 5$ th MIC levels of $2.27 \mathrm{mM} \mathrm{CA}$ and $3.62 \mathrm{mM} \mathrm{SA}$ in either single or combination treatments. A 
positive control for QS was included using $10 \mu \mathrm{M} \mathrm{C} 30 \mathrm{~F}$ (Skindersoe et al. 2008). All experiments were carried out in biological triplicates. The experimental compounds were purchased from Sigma-Aldrich, UK, unless otherwise stated.

\section{Minimum inhibitory concentration determination}

The minimum inhibitory concentration (MIC) of the test inhibitors against $P$. aeruginosa PAO1 was determined using the resazurin microtiter plate assay (Elshikh et al. 2016) which used the redox indicator resazurin that changed colour from blue to pink in the presence of viable cells. The MIC was determined as the concentration at which there was no colour change following $4 \mathrm{~h}$ incubation of the overnight cells with $0.015 \%$ resazurin.

\section{RNA isolation and purity assessment}

The cell pellets were collected from different growth phase cultures by spinning them at $13,000 \times g$ for 2-3 min at room temperature and the RNA extracted using JetGene RNA Purification Kit (Thermo Fisher Scientific). The cells were lysed with occasional vortexing in a buffer solution with $1 \times$ TE buffer, $15 \mathrm{mg} / \mathrm{ml}$ lysozyme and $20 \mathrm{mg} / \mathrm{ml}$ proteinase $\mathrm{K}$ (Promega). The samples were then transferred to a 2-ml Lysing Matrix A tube (MP Biomedicals) with $\beta$-mercaptoethanol containing RLT buffer (provided in the kit) for enhanced lysis. The contents in the lysing matrix tubes were then homogenised using the FastPrep ${ }^{\mathrm{TM}} \mathrm{FP}$ 200 cell disrupter at speed 5.5 for $30 \mathrm{~s}$. A double DNA-digestion treatment was done to ensure that the RNA was free of any genomic DNA (gDNA) contamination. The RNA isolated was quantified using the Nanodrop spectrophotometer with $\mathrm{A}_{260} /$ $\mathrm{A}_{280}$ ratio of 1.8-2.1 being considered as pure. The integrity of the samples was checked by agarose gel electrophoresis for presence of two sharp distinct bands representing $23 \mathrm{~S}$ and $16 \mathrm{~S}$ rRNA. The integrity was further verified by analysing the samples in an Agilent 2100 Bioanalyzer where RNA Integrity Number (RIN) values greater than 8 were observed for all samples. The RIN is based on a numbering system from 1 to 10 with 1 being the most degraded and 10 being the most intact. The RNA samples were aliquoted and stored at $-80^{\circ} \mathrm{C}$.

\section{Reverse transcription quantitative polymerase chain reaction}

First-strand cDNA was synthesised using Superscript ${ }^{\mathrm{TM}}$ Reverse Transcriptase II (Invitrogen). Each reaction mix contained DNase-treated RNA (500 ng), 20-250 ng random primers (Promega), $10 \mathrm{mM}$ dNTPs and RNase free water to make to the reaction volume $15.6 \mu \mathrm{l}$. The reactions were heated at $65{ }^{\circ} \mathrm{C}$ for $5 \mathrm{~min}$ before adding $5 \times$ strand buffer, $0.1 \mathrm{M}$ DTT and RNase inhibitor (RNAse out ${ }^{\mathrm{TM}}$ Invitrogen) in final concentrations of $1 \times, 10 \mu \mathrm{M}$ and 40 units, respectively. The reactions were incubated at $25^{\circ} \mathrm{C}$ for $2 \mathrm{~min}$ before adding Superscript ${ }^{\mathrm{TM}} \mathrm{II}$
Reverse Transcriptase (200 units final concentration) (Invitrogen). The RT reactions were carried out at a series of temperature starting with $25^{\circ} \mathrm{C}$ for $10 \mathrm{~min}, 42^{\circ} \mathrm{C}$ for $50 \mathrm{~min}$ and $70{ }^{\circ} \mathrm{C}$ for $15 \mathrm{~min}$. The first-strand cDNA synthesis was performed for all the biological triplicates from each time point. A negative reaction without reverse transcriptase was included in every run. All cDNA samples were stored at $-20^{\circ} \mathrm{C}$ prior to use.

The cDNA synthesised was then used as a template for realtime PCR amplification using the ROCHE LightCycler LC480 system with a SYBR-Green probe. Since PCR efficiency is highly dependent on primer specificity, therefore a qPCR calibration curve was generated from each primer set using PAO1 gDNA. Only those primers which gave a calibration curve with a slope value between -3.1 and -3.6 that translated into amplification efficiencies of $90-110 \%$ were used for PCR quantification. The binding specificity of these primers were also validated post-amplification by generating a melt curve for each primer set with the presence of a single sharp peak eliminating the chances of any non-specific binding.

The qPCR $10 \mu 1$ reaction mix each contained $2 \times$ SYBR Green master mix $(1 \times)$, forward and reverse primers $(1 \mu \mathrm{M})$, cDNA template and molecular grade water. Negative controls in form of -RT (no reverse transcriptase) and no template control NTC (no DNA template added) were included to rule out any contamination during the preparation process. A positive control in the form of gDNA was also included. The cutoff values for residual gDNA amplification and NTC were set at greater than 35 and 40 cycles, respectively. The cycling parameters were as follows: initial denaturation at $95^{\circ} \mathrm{C}$ for 5 min, $40-50$ cycles of denaturation at $95^{\circ} \mathrm{C}$ for $10 \mathrm{~s}$, annealing at $59^{\circ} \mathrm{C}$ for $10 \mathrm{~s}$, extension at $72{ }^{\circ} \mathrm{C}$ for $10 \mathrm{~s}$.

\section{Reference gene validation}

A total of six candidate genes (gyrB, proC, cys $G, r p o D, r p o B$ and $16 S$ ) were analysed under inhibitory conditions to assess for the most stable and reliable reference genes for this study. The stability of the six candidate genes were validated under inhibitory conditions using three independent software packages geNorm (Vandesompele et al. 2002), NormFinder (Andersen et al. 2004) and BestKeeper (Pfaffl et al. 2004). The geNorm algorithm measures the stability of the genes based on pairwise variation between one candidate gene and the other genes and was calculated using the online available tool RefFinder (Fu et al. 2013). The NormFinder model considers the intra- and inter-group variation to calculate the stability of the genes using a R-based software excel package (MOMA, Aarhus University Hospital, Denmark). The BestKeeper is a free excel-based tool that correlated the coefficient of the candidate gene with a BestKeeper Index to generate the most stable gene. The genes $r p o D$ and $p r o C$ were identified as most stable for use as reference genes in this study by the three algorithms. 


\section{Relative gene expression data analysis}

System (LC480 software, version 2)-generated analysis was performed on the real-time PCR data. The threshold values (Cq) from each of the qPCR run were extracted from the LC480 system using the second derivative maximum method (Rasmussen 2001). Data analysis was performed by taking the arithmetic mean of the $\mathrm{Cq}$ values of the technical replicates and transferring it into log values to generate the relative quantities (RQ). The RQ values of the target genes were then divided by geometric mean of reference gene RQs (rpoD and $p r o C)$ to give normalised relative quantity value (NRQ). The NRQ value was then divided by the experimental calibration which in the experiment was relative expression at early log (6-h) and was set to 1 . The output was the calibration normalised ratio (CNRQ) which was used in extrapolating information on the expression profile of the target genes.

\section{Production of virulence factors}

An overnight PAO1 culture was used to inoculate PPGAS medium and incubated for $24 \mathrm{~h}$ under continuous shaking at $37^{\circ} \mathrm{C}$. The supernatant was collected, and filter sterilised for use in the following assays:

Protease The amount of LasA protease produced by PAO1 following incubation with and without the inhibitors were estimated by adding $0.1 \mathrm{ml}$ culture supernatant to a reaction mixture containing $0.8 \%$ azocasein in $500 \mu \mathrm{l}$ of $50 \mathrm{mM}$ $\mathrm{K}_{2} \mathrm{HPO}_{4}(\mathrm{pH} 7)$ and incubating at $25^{\circ} \mathrm{C}$ for $3 \mathrm{~h}$. The reaction was terminated by adding $0.5 \mathrm{ml}$ of $1.5 \mathrm{M} \mathrm{HCl}$ and then keeping it on ice for $30 \mathrm{~min}$. The precipitated protein was removed by centrifugation $(10,000 \times g$ for $10 \mathrm{~min})$. $\mathrm{NaOH}$ $(1 \mathrm{~N})$ was added to the supernatant in equal ratios and the concentration of acid soluble azopeptides measured spectrophotometrically at $440 \mathrm{~nm}$.

Elastase The LasB elastase production was measured by adding $1 \mathrm{ml}$ of the culture supernatant to a 2-ml reaction buffer $(100 \mathrm{mM}$ Tris- $\mathrm{HCl}, 1 \mathrm{mM} \mathrm{CaCl}_{2}$ ) containing the substrate elastin-Congo red and incubating for $3 \mathrm{~h}$ at $37^{\circ} \mathrm{C}$ with shaking at $180 \mathrm{rpm}$. The reaction was terminated by adding $2 \mathrm{ml}$ of $0.7 \mathrm{M}$ sodium phosphate buffer ( $\mathrm{pH} 6$ ) and placing it on ice for $15 \mathrm{~min}$. The absorbance of the supernatant was measured at $495 \mathrm{~nm}$.

Pyocyanin The pyocyanin concentration was estimated by adding $7.5 \mathrm{ml}$ filtered supernatant to $4.5 \mathrm{ml}$ of chloroform and vortexed until the colour changed to greenish blue. The samples were centrifuged $(10,000 \times g$ for $10 \mathrm{~min})$ and $3 \mathrm{ml}$ of the resulting blue coloured liquid was transferred to a new tube containing $1.5 \mathrm{ml}$ of $0.2 \mathrm{M} \mathrm{HCl}$ and shaken until the blue colour turned to pink. The pink layer was transferred to a cuvette and the absorbance measured at $520 \mathrm{~nm}$. The concentration was calculated in $\mu \mathrm{g} / \mathrm{ml}$ by multiplying the absorbance by factor 17.072 (Essar et al. 1990).

\section{Rhamnolipid extraction and purification}

The extraction of rhamnolipid was performed following the method of Smyth et al. (2010). The culture supernatant $(50 \mathrm{ml})$ from PAO1 grown in PPGAS medium for $24 \mathrm{~h}$ was acidified to $\mathrm{pH} 2$ and extracted with ethyl acetate three times. The organic solvent containing rhamnolipid was dried with anhydrous $\mathrm{MgSO}_{4}$ to remove residual water. Rhamnolipid was isolated from the ethyl acetate solvent in the form of yellow gummy residue after removing the organic solvent in a rotary evaporator. The rhamnolipid crude extract was then purified using solid phase extraction by running the samples through Strata SI-1 Silica (55 $\mu \mathrm{M}, 70 \mathrm{~A})$ Giga tubes (Phenomenex). After conditioning and removing the impurities from the column with chloroform, rhamnolipids were eluted using chloroform and methanol in ratios of 5:0.3, 5:0.5 and 1:1.

\section{Rhamnolipid separation and analysis by high-performance liquid chromatography mass spectrometry/mass spectrometry}

Analysis of the extracted rhamnolipid mixture was performed using a $\mathrm{LCQ}^{\mathrm{TM}}$ quadrupole ion trap with a negative electrospray ionisation (ESI) interface connected to a Thermo HPLC Spectra system. A reverse phase $\mathrm{C} 18$ column with $5 \mu \mathrm{m}$ particles was used to separate the rhamnolipids. The parameters included desolvation gas at 65 units and source temperature $250{ }^{\circ} \mathrm{C}$, $20 \mu \mathrm{l}$ injection volume and $0.5 \mu \mathrm{l} / \mathrm{min}$ flow rate. Two mobile phases were used: HPLC grade water (A) and acetonitrile (B). The rhamnolipid congeners were resolved in a linear gradient mobile phase starting with $70 \% \mathrm{~A}: 30 \% \mathrm{~B}$ to $30 \% \mathrm{~A}: 70 \% \mathrm{~B}$ over $50 \mathrm{~min}$ and then back to $70 \% \mathrm{~A}: 30 \% \mathrm{~B}$ for $55 \mathrm{~min}$ with a final hold of $5 \mathrm{~min}$. Tandem mass spectrometry was carried out using ESI in a negative mode using collision-induced dissociation (CID) at $35 \%$ peak within the MS range of 50-800 m/z.

\section{Statistical analysis}

All statistical analysis was performed using the GraphPad prism v5.

\section{Results}

\section{Growth phase-dependent expression of QS genes}

The effect of the QSIs on the QS system of the fully sequenced laboratory strain P. aeruginosa PAO1 (Stover et al. 2000) was investigated by studying the transcriptional expression of the QS synthase and regulatory genes. Both lasR/lasI and rhlR/rhlI 
systems were expressed in a cell density-dependent manner with expression levels increasing upon entering the stationary phases of growth (Fig. 1b). Maximum expression levels for all genes were detected in the mid-late stationary phase corresponding with highest cell density. In both las and rhl systems, the autoinducer synthase genes (lasI and $r h l l$ ) were expressed earlier and at much higher relative concentrations in comparison to their cognate regulatory protein genes (lasR and $r h l R$ ). At high concentrations, LasR and RhlR bind to their cognate N-acyl homoserine autoinducer molecules; the bound complex is then a transcriptional regulator of several genes in P. aeruginosa.

The QS system regulates productions of most of the $P$. aeruginosa virulence factors including the low molecular weight glycolipids rhamnolipids that are under the direct regulation of the RhlR-RhlI system. The rhamnolipid biosynthetic genes display a differential expression profile where rhlA and $r h l B$ are expressed earlier relative to $r h l C$, which is only maximally expressed after significant $r h l A B$ expression (Fig. $2 \mathrm{a}-\mathrm{c}$ ). The products of $\operatorname{rhl} A B$ are responsible for the first step in rhamnolipid biosynthesis, which produce monorhamnolipids. Mono-rhamnolipids are in turn the substrate for the $r h l C$ gene product to produce di-rhamnolipids. The differential sequential expression pattern observed for the rhamnosyltransferases from this data is suggestive of a coordinated regulation based on the substrate availability.

The other virulence-associated genes responsible for the production of the exoprotease LasA, and elastase LasB, were also transcriptionally expressed in a cell density-dependent
Fig. 1 Las and $r h l$ QS regulatory genes in P. aeruginosa PAO1 are differentially expressed in a cell density-dependent manner. a Growth of $P$. aeruginosa in phosphate-limited media (PPGAS). b Transcriptional expression of QS regulatory genes lasR, lasI, rhlR and rhlI. Expression levels were quantified by RT-qPCR, relative mRNA levels for target genes were normalised to the geometric mean of two reference genes $(r p o D$ and proC) and values plotted are the mean calibrator normalised ratios to $\log$ phase $(6 \mathrm{~h})$. Vertical bars represent S.D. $\pm(n=3)$. Data was analysed using one-way ANOVA followed by Dunnett's multiple comparison test $(* * p<0.01$, $* * * p<0.001)$

a

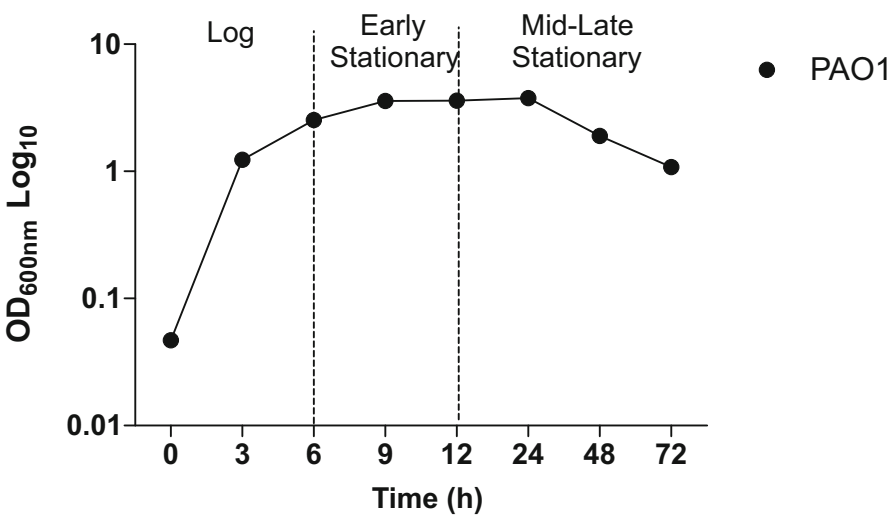

b

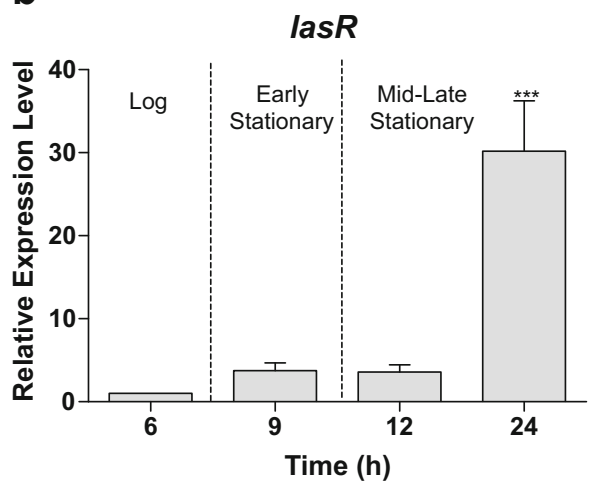

$r h I R$

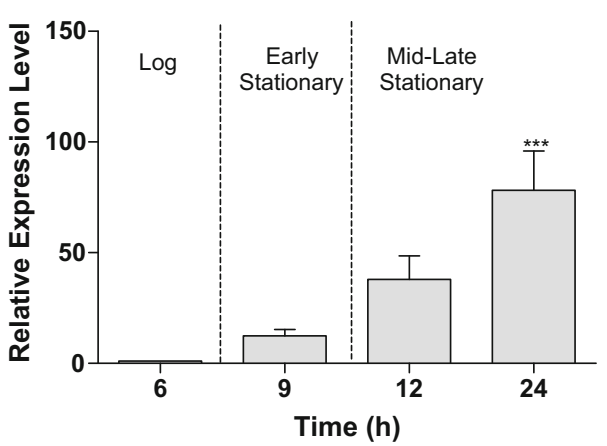

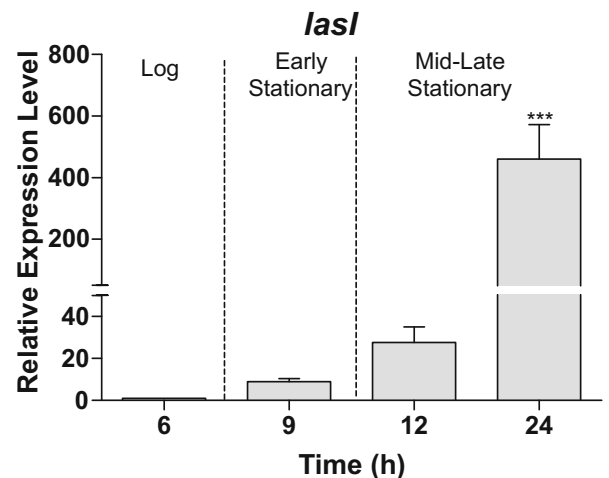

rhll

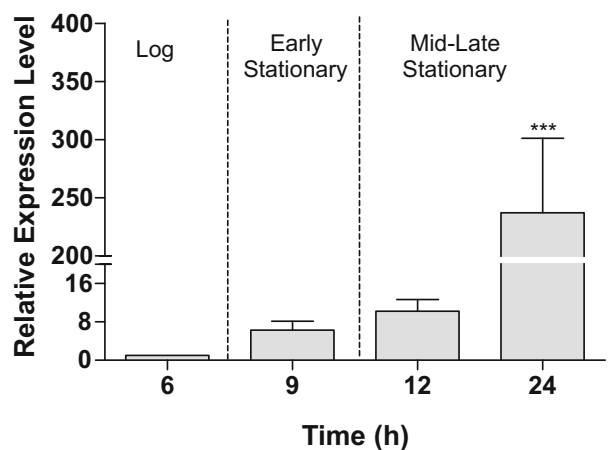


Fig. 2 QS-regulated virulenceassociated genes are highly expressed in stationary phase in $P$. aeruginosa PAO1. Relative transcript levels of virulenceassociated rhamnolipid biosynthetic genes a $r h l A, \mathbf{b} r h l B$, c $r h l C$ and exoprotease $\mathbf{d}$ las $A$ and elastase e las $B$. Relative mRNA levels for target genes were normalised to the geometric mean of two reference genes $(r p o D$ and pro $C$ ) and values plotted are the mean calibrator normalised ratios to log phase $(6 \mathrm{~h})$. Vertical bars represent S.D. $\pm(n=3)$. Data was analysed using one-way ANOVA followed by Dunnett's multiple comparison test $(* p<0.05$, $* * p<0.01, * * * p<0.001)$ a

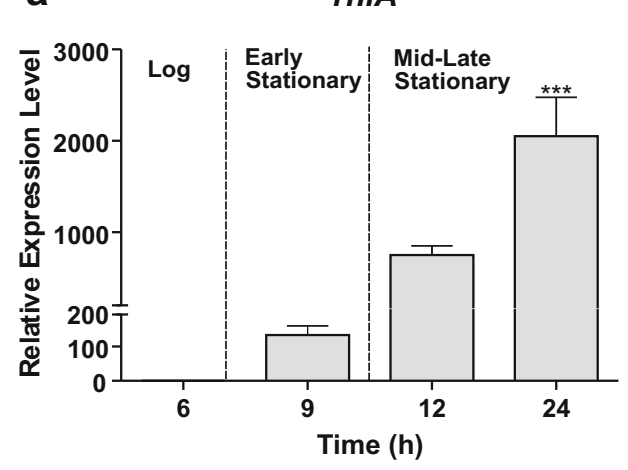

b

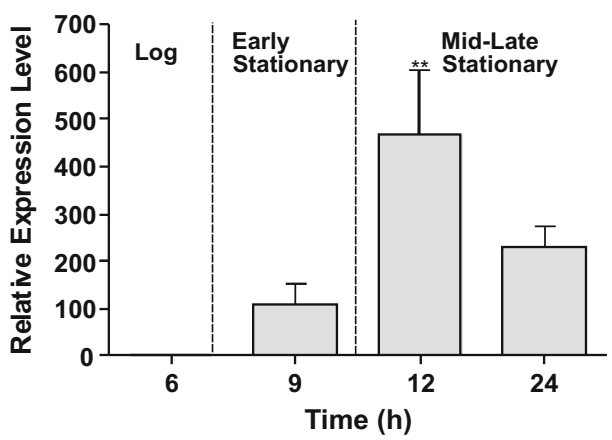

C

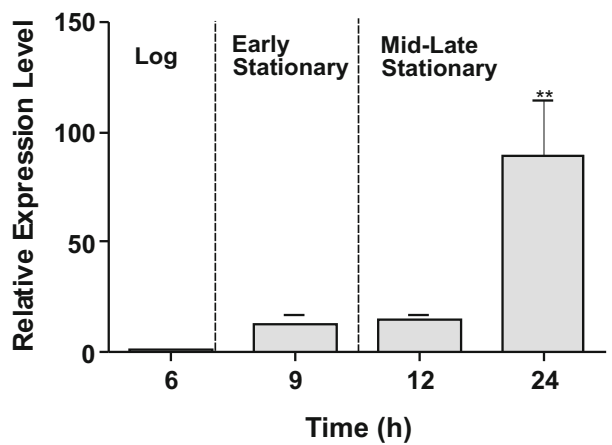

d

las $A$

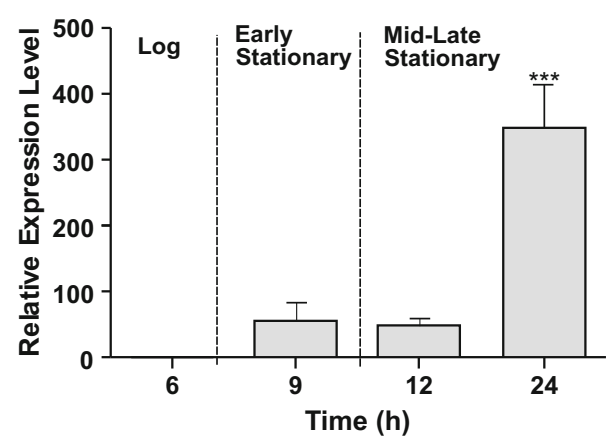

e

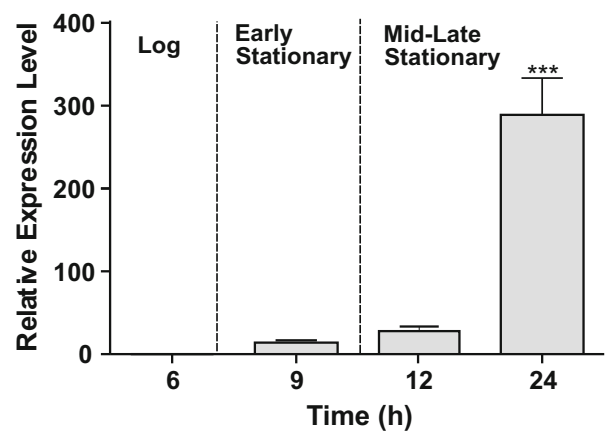

manner with maximum expression observed in mid-late stationary phase (Fig. 2d-e). The las-regulated virulence genes las $A$ and $\operatorname{las} B$ were shown to be significantly upregulated during the mid-late stationary phase with expression levels $>300$-fold relative to log phase levels $(p<0.001)$.

\section{Quorum sensing inhibitors effectively downregulate the QS regulatory system}

Selectively interfering with QS systems is a novel strategy targeted at disarming virulent opportunistic pathogens such as $P$. aeruginosa. In Gram-negative bacteria, QS is typically mediated by acyl-HSLs and rational analogues have been designed to specifically target these systems. Several phenolic compounds have been be shown to effectively disrupt QS systems in Gram-negative bacteria (Hossain et al. 2017). In this part of the study, we investigated the anti-QS abilities of naturally isolated plant compounds $\mathrm{CA}, \mathrm{SA}$ and a synthetic furanone compound, $\mathrm{C} 30 \mathrm{~F}$, reported to attenuate virulence in P. aeruginosa (Fig. 3a) (Hentzer et al. 2003; Yang et al. 2009; Chang et al. 2014). The minimum inhibitory concentration (MIC) of the test compounds CA and SA was determined as $11.35 \mathrm{mM}$ and $18.1 \mathrm{mM}$, respectively. The use of the quorum sensing inhibitors (QSIs) at the sub-inhibitory concentrations (1/5th MIC) did not affect the growth phenotype of P. aeruginosa PAO1 (Fig. 3b). CA treatment resulted in a longer lag phase but reached similar optical densities to untreated PAO1 within $6 \mathrm{~h}$ of incubation. Since QS genes were significantly expressed in the stationary phase (Fig. 1b), we tested the effect of the QSIs on the expression of QS- 
a<smiles>O=C(O)c1ccccc1O</smiles><smiles>O=C/C=C/c1ccccc1</smiles><smiles>O=C1C=C(Br)/C(=C/Br)O1</smiles>

b

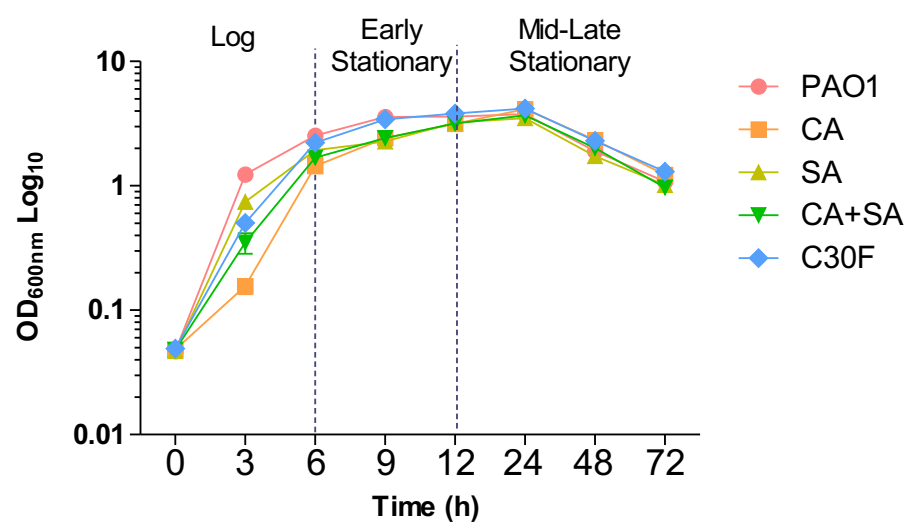

C
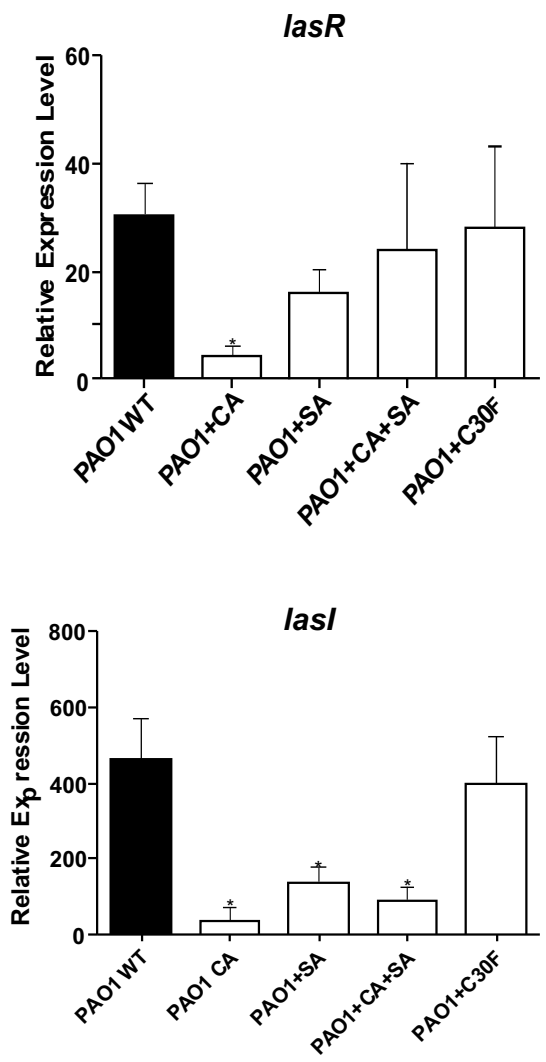

Fig. 3 Quorum sensing inhibitors (QSIs) significantly reduce expression of las and $r h l$ QS systems in P. aeruginosa. a Molecular structure of the natural QSIs used in this study, salicylic acid (SA), trans-cinnamaldehyde (CA) and positive control furanone C30 (C30F). b Growth of $P$. aeruginosa with QSIs at sub-MIC concentrations (SA $3.62 \mathrm{mM}$, CA $2.27 \mathrm{mM}$ and C30F $10 \mu \mathrm{M}$ ). c Relative

associated regulatory and virulence genes during mid to late stationary phase of growth, when the cell density was at its highest.
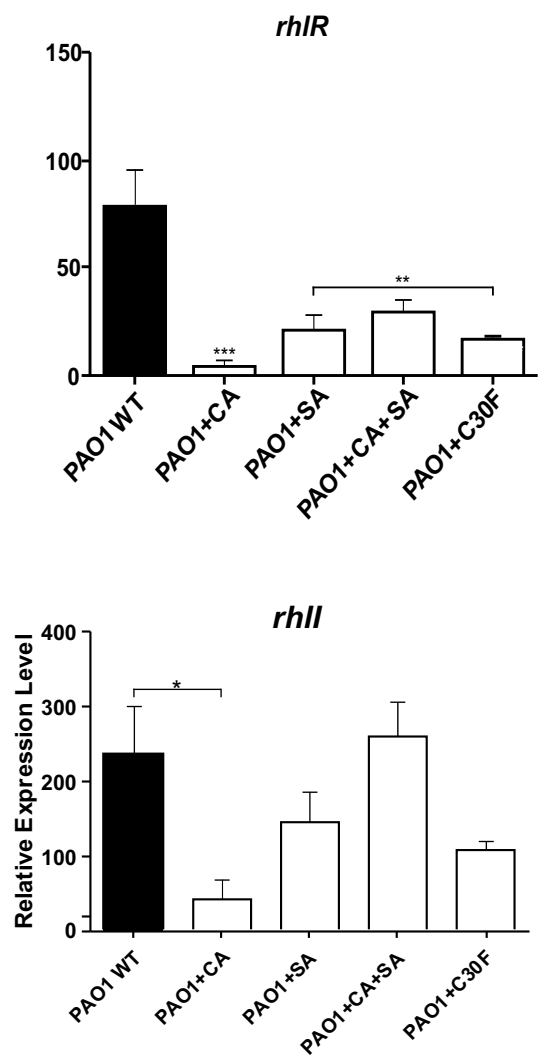

expression of QS regulatory genes lasR, las $I$, rhlR and rhlI with combinations of QSI treatments. Relative mRNA levels for target genes were normalised to the geometric mean of two reference genes (rpoD and proC). Vertical bars represent S.D. $\pm(n=3)$. Data was analysed using two-way ANOVA followed by Bonferroni post-tests $(* * p<0.01, * * * p<0.001)$

CA at sub-inhibitory levels $(2.27 \mathrm{mM})$ significantly $(p<0.001)$ reduced the expression of the QS transcriptional regulatory genes lasR and rhlR (Fig. 3c). CA caused a 7-fold 
reduction $(p<0.001)$ in las $R$ gene expression while the difference between the untreated and treated cells was even higher in the LasR-controlled rhlR expression with a reduction of 19-fold being observed. CA also effected a significant $(p<0.001)$ reduction in the AHL synthase gene expressions during the stationary phase of growth. The downregulation in the rhlI synthase gene following treatment was 6-fold while in lasI synthase, it was 13fold during the late stationary phase.

The second inhibitor tested was the plant hormonal compound SA at sub-inhibitory concentration of $3.62 \mathrm{mM}$. This also caused inhibition in QS gene expressions but unlike CA, the overall reductions were lower (Fig. 3c). The compound seemed to have a greater inhibitory effect on the las QS circuit unlike CA which effectively repressed both las and $r h l$ QS synthase and regulatory genes. The downregulation in QS transcriptional regulatory genes las $R$ and $r h l R$ due to SA treatment was 2-fold and 4-fold, respectively. The transcript levels of the lasI synthase gene were three times lower following SA treatment, while there was no significant reduction in expression of the rhlI synthase gene in the stationary phase. The behaviour of the las $R$ and $r h l R$ regulatory genes determines the expression of virulence-related genes associated with the QS mechanisms in P. aeruginosa; therefore, these results suggest that SA would not produce a very high downregulation in QS-regulated virulence gene expressions in comparison to CA.

Although CA and SA when used alone did show reduction in most QS gene transcripts but when used in combination $(\mathrm{PAO} 1+\mathrm{CA}+\mathrm{SA})$ the results were inconclusive (Fig. 3c). The combination treatment influenced the lasI synthase expression where it reduced the transcript level by 5 -fold. A similar reduction (3-fold) was also observed in the transcriptional regulator $r h l R$ expression. However, the combination treatment did not exert any significant effect on the expression levels of the lasR and rhlI genes. These results suggest that the inhibitory effects of CA and SA on the QS gene transcriptions were compromised when used in combination.

The positive control C30F produced an expected inhibitory effect on the $r h l$ circuit of $P$. aeruginosa during the mid-late stationary phase when used at a concentration of $10 \mu \mathrm{M}$ (Fig. 3c). The rhlR transcript level was reduced 5-fold while the synthase gene rhlI was repressed by 2 -fold. The compound did not produce any significant inhibition on the transcription levels of the lasRI genes.

\section{Trans-cinnamaldehyde significantly reduces expression of QS-regulated virulence factors}

After investigating the effect of the experimental inhibitors on the QS master genes - lasRI and rhlRI, the study focused on investigating the inhibitory effects on the las and $r h l$ QS-regulated set of virulence genes. The target genes selected were las-controlled las $A$ protease and las $B$ elastase and $r h l$-regulated genes $r h l A$, $r h l B$ and $r h l C$ associated with rhamnolipid production (Fig. 4a).
The target gene expression was normalised using validated reference genes, $r p o D$ and $p r o C$, across all culture conditions.

The significant inhibition in lasRI expressions in $P$. aeruginosa PAO1 when subjected to $\mathrm{CA}$ as seen before affected the mRNA transcript levels of the lasA and las $B$ genes (Fig. 4b). The relative expression data showed a 19 -fold $(p<0.001)$ reduction in las $A$ gene expression while las $B$ showed a 7-fold $(p<0.001)$ reduction when compared to the untreated cells during the mid-late stationary growth phase. The compound was also effective in highly repressing the expression of the rhamnolipid synthesis $r h l A B C$ genes during stationary phase (Fig. 4b). The reduction in transcript level of rhlA was observed as greater than 100 -fold $(p<0.001)$. A significantly high downregulation was also observed in $r h l B(p<0.05)$ expression while a 2 -fold reduction $(p<0.05)$ was observed in $r h l C$ expression.

The ability of SA to repress the las QS genes lasI and lasR (Fig. 3c) consequently influenced the virulence gene expressions of las $A$ and las $B$. The transcript levels of lasA and las $B$ were reduced by 4 -fold $(p<0.001)$ and 2 -fold $(p<0.01)$ respectively when treated with $3.62 \mathrm{mM} \mathrm{SA}$ (Fig. 4c). It can be hypothesised that the inability of SA to produce an inhibitory effect on rhlI synthase gene expression (Fig. 3c) meant there were enough signal molecules to drive the expression of the rhlABC genes. Although a 3 -fold $(p<0.001)$ reduction was observed in rhlA gene expression, partly due to the reduced expression of the rhlR regulatory gene, the overall inhibitory effect seemed small as insignificant reductions in $r h l B$ and $r h l C$ gene expressions were observed with SA at the concentration tested in this experiment (Fig. 4c).

The downregulation in the lasI synthase gene when treated with both $2.27 \mathrm{mM} \mathrm{CA}$ and $3.62 \mathrm{mM}$ SA did not correlate in a mRNA reduction of the las-regulated virulence genes lasA and lasB (Fig. 4d). However, the ability of the combination treatment to repress the QS regulatory rhlR gene caused a significant downregulation $(p<0.001)$ in the rhlAB genes. The combination treatment exerted a 4-fold decrease in the rhlA gene and 6-fold decrease in the $r h l B$ gene expressions compared to the untreated samples. Interestingly, a minor upregulation of 2-fold was observed in the $r h l C$ gene.

The inability of $\mathrm{C} 30 \mathrm{~F}$ to reduce las-regulated QS regulatory and synthase gene expressions was only validated in the target gene expression analysis with no reduction being observed in las-controlled virulence las $A$ and $\operatorname{las} B$ expressions (Fig. 4e). But C30F's ability to reduce rhlRI had a consequential effect on the expression of $r h l A B$ genes with reduction of 2-fold and 3-fold in rhlA and rhlB gene expressions respectively at late-mid stationary phases.

\section{QSIs reduce production of extracellular virulence factors at sub-MIC concentrations}

Biofilm formation The ability of $P$. aeruginosa PAO1 to form biofilm was assessed using a widely employed in vitro model 
Fig. 4 Trans-cinnamaldehyde (CA) significantly reduces gene expression of virulenceassociated genes in $P$. aeruginosa PAO1. a The schematic representation of the genetic location of las and rhl QS systems in P. aeruginosa. Effect of QSIs at the following concentrations of $\mathbf{b}$ $2.27 \mathrm{mM} \mathrm{CA}, \mathbf{c} 3.62 \mathrm{mM} \mathrm{SA}$, d $2.27 \mathrm{mM} \mathrm{CA}+3.62 \mathrm{mM} \mathrm{SA}$ and e $10 \mu \mathrm{M} \mathrm{C} 30 \mathrm{~F}$ on the transcriptional expression of virulence-associated genes lasA, lasB, rhlA, rhlB and rhlC in P. aeruginosa $\mathrm{PAO} 1$. Gene expression was quantified at $24 \mathrm{~h}$ for both treated and untreated cells, relative mRNA levels for target genes were normalised to the geometric mean of two reference genes (rpoD and proC). Vertical bars represent S.D. $\pm(n=$ 3). Data was analysed using twoway ANOVA followed by Bonferroni post-tests $(* p<0.05$, $* * p<0.01, * * * p<0.001)$

a

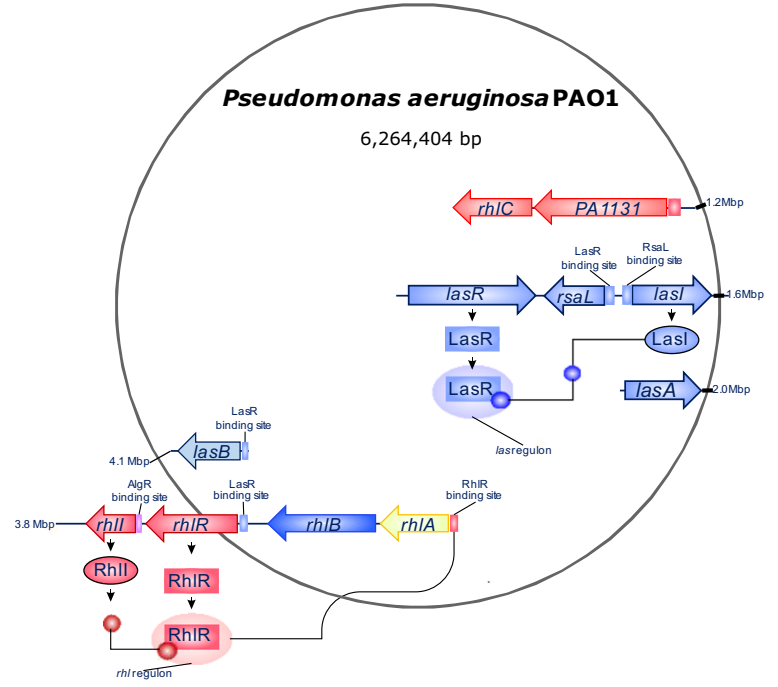

b

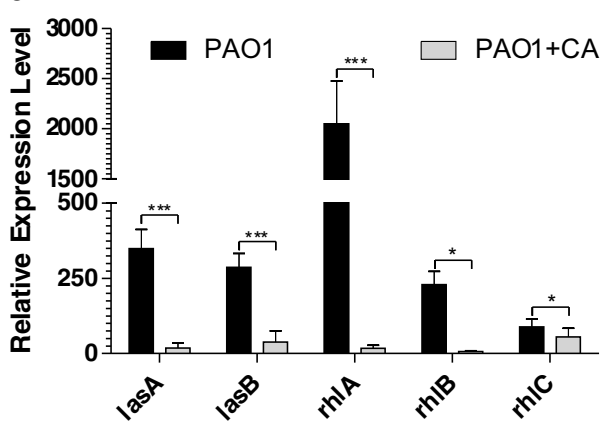

d

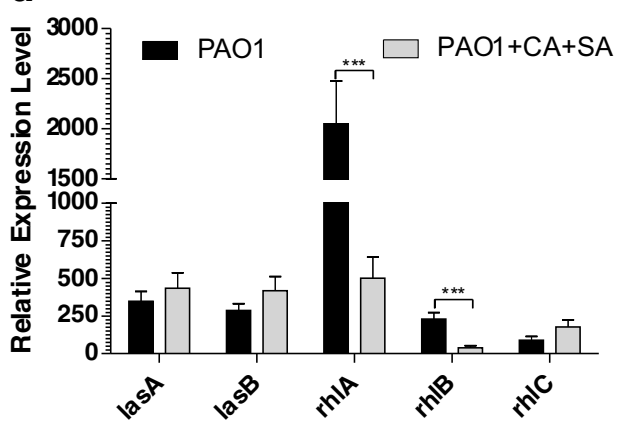

C

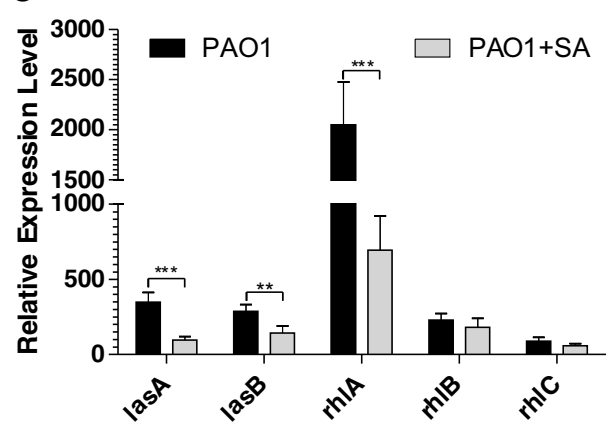

e

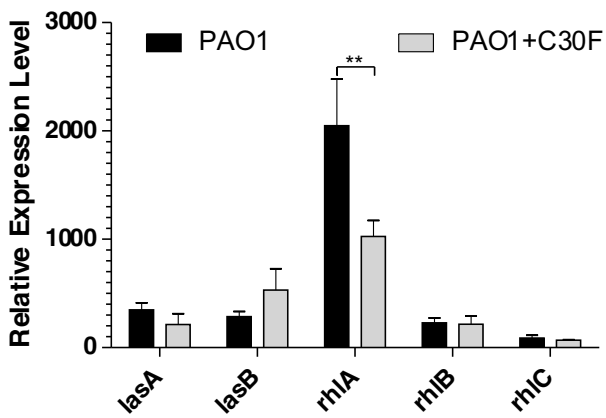

outlined by O'Toole (2011) with slight modifications. The biofilm growth was visualised as a ring of biomass stained with crystal violet at the air-liquid interface. The biofilm formation was evaluated both in the presence and absence of inhibitory compounds, by measuring the absorbance of crystal-violetstained-adherent-cells solubilised in ethyl acetate at $570 \mathrm{~nm}$ from stationary phase cultures (24-h) (Fig. 5a). There were significant $(p<0.001)$ reductions in treated samples compared to the untreated PAO1. In comparison to CA, SA was more effective in reducing the formation of biofilm in the microtiter wells with an absorbance reduction of 54\% compared to the untreated cells. CA was also effective, to a lesser degree, with reductions of $26 \%$. The combined use of CA and SA was the most effective of the treatment methods with a reduction of $62 \%$. The positive control $\mathrm{C} 30 \mathrm{~F}$ in comparison was the least effective (24\%) in reducing biofilm formation.

LasA protease There were significant reductions in LasA protease activity in the QSI-treated cells as estimated from absorbance reading resulting from azo dyes released into the medium due to proteolytic cleavage of the substrate azocasein. In the presence of SA, the $\mathrm{OD}_{440}$ dropped from 0.3 to 0.1 to account for a $31 \%$ reduction $(p<0.05)$ in absorbance reading while CA treatment gave an even higher reduction of $65 \%$ $(p<0.01)$. The combination QSIs $(\mathrm{CA}+\mathrm{SA})$ treatment produced the highest reduction in protease production with a 
Fig. 5 QSIs quantitatively reduce production of extracellular virulence factors in $P$. aeruginosa PAO1. QS-regulated phenotypes a biofilm formation and extracellular factors b protease, $\mathbf{c}$ elastase and $\mathbf{d}$ pyocyanin were significantly disrupted by QSIs. The percentage reductions mentioned were calculated against the untreated PAO1. Error bars represent S.D. $\pm(n=3)$. Data was analysed using one-way ANOVA followed by Dunnett's multiple comparison test $(* p<0.05, * * p<0.01$, $* * * p<0.001)$
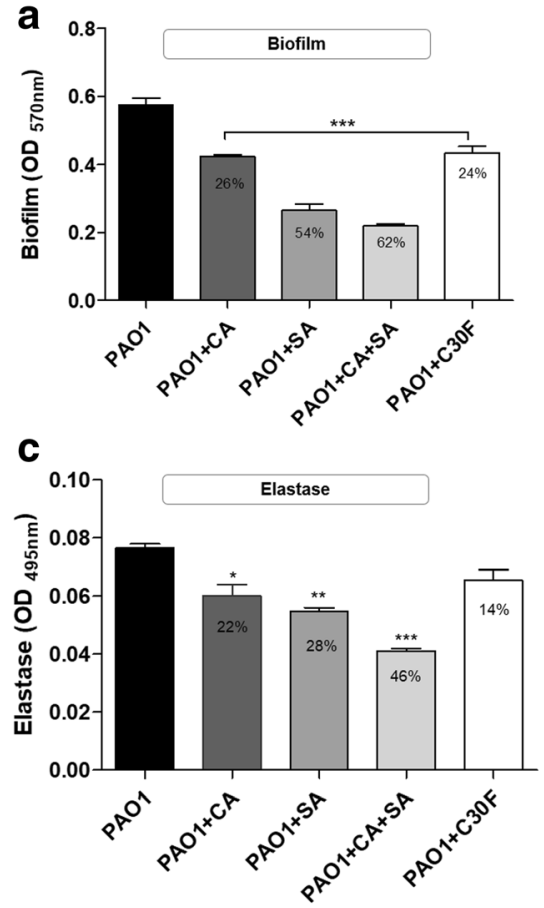

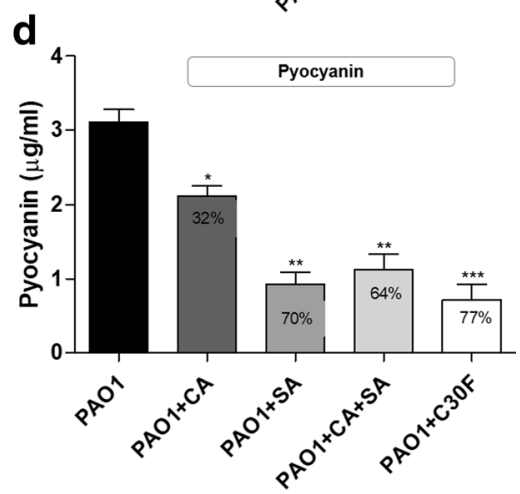

reduction of $80 \%(p<0.001)$ absorbance being observed when compared to the untreated PAO1 (Fig. 5b).

LasB elastase The elastase production was estimated through absorbance measurement of Congo red following cleavage of elastin-Congo red substrate by the enzyme elastase produced by $P$. aeruginosa. In presence of inhibitors $\mathrm{CA}$ and SA, the $\mathrm{OD}_{495}$ decreased from 0.08 to 0.06 and 0.05 respectively giving subsequent reduction percentages of $22 \%(p<0.01)$ and $28 \%(p<0.05)$ (Fig. 5 c). The combination treatment was again the most effective in reducing absorbance with reduction of $46 \%$. However, like the protease assay, C30F was the least effective, confirming earlier results of its reduced inhibitory effects on las $A$ and $l a s B$ gene expressions.

Pyocyanin Pyocyanin production is regulated by the $r h l \mathrm{QS}$ via PQS; hence, the measurement of pyocyanin inhibition is also a good indicator of the effectiveness of the tested compounds as QS inhibitors in P. aeruginosa. The pyocyanin concentration decreased from $3.1 \mu \mathrm{g} / \mathrm{ml}$ to $2.1 \mu \mathrm{g} / \mathrm{ml}$ and $0.922 \mu \mathrm{g} / \mathrm{ml}$ in the presence of CA and SA, respectively. When used together, the inhibitors decreased the yield by $64 \%(1.1 \mu \mathrm{g} / \mathrm{ml})$ (Fig. $5 \mathrm{~d})$.

Rhamnolipid estimation The administration of the QS inhibitors caused a reduction in the yield of rhamnolipid with CA and SA both producing a drop in crude weight from $1.72 \mathrm{~g} / 1$ to $0.7 \mathrm{~g} /$ 1 (approximately) (Fig. 6a). Rhamnolipids are produced as congeners containing one to two rhamnose sugar moieties giving the compounds their distinctive properties (Chen et al. 2010; Chen et al. 2013). The structural composition of rhamnolipid produced in the presence of the QSIs was studied by analysing the purified crude sample using high-performance liquid chromatography mass spectrometry/mass spectrometry (HPLC-MS/ MS) method. The inhibitor treatment when used alone did not affect the composition of the rhamnolipid with the congener profile resembling the untreated PAO1 sample (Fig. 6c). But in the combination treatment $(\mathrm{PAO} 1+\mathrm{CA}+\mathrm{SA})$, only two rhamnolipid congeners were detected by the HPLC-MS/MS method (Fig. 6d) compared to six in the untreated sample. This combination treatment also effected the maximum reduction in the relative amount of rhamnolipid obtained from a 50-ml culture supernatant. The two predominant congeners identified in all the samples were Rha-Rha- $\mathrm{C}_{10}-\mathrm{C}_{10}(\mathrm{~m} / \mathrm{z}, 649)$ and RhaRha- $\mathrm{C}_{10}-\mathrm{C}_{12}(\mathrm{~m} / \mathrm{z}, 677)$. The mono-rhamnolipid detected in greatest abundance was $\mathrm{Rha}-\mathrm{C}_{10}-\mathrm{C}_{10}$. When the MS data for the two common di-rhamnolipid congeners were compared to untreated sample, the combination treatment and CA treatment showed marked differences (Fig. 6b). SA treatment did not show any noticeable difference in relative quantification of the congeners although it resulted in a decrease in crude weight.

\section{Discussion}

\section{Trans-cinnamaldehyde is more effective than salicylic acid in reducing expression of QS genes}

This study is consistent with previous research showing that natural QSIs significantly modulate transcriptional expression of QS regulatory and virulence-associated genes during 


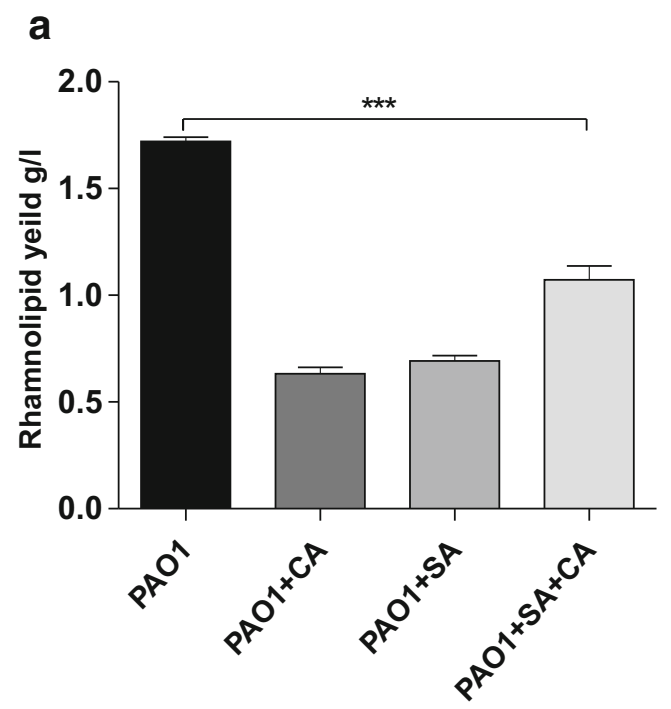

C

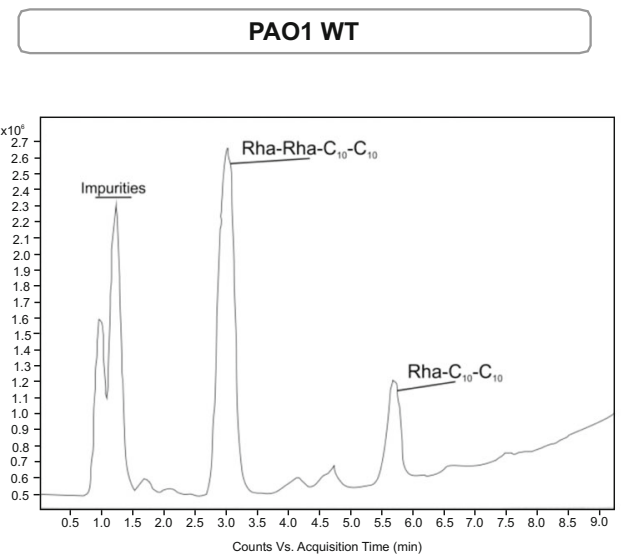

Fig. 6 QSIs significantly reduce $r h l$-regulated rhamnolipid production $P$. aeruginosa. a The QSIs reduces the rhamnolipid crude yield significantly compared to the untreated PAO1 cells. b \% reduction in the two main RL congeners Rha- $\mathrm{C}_{10}-\mathrm{C}_{10}$ and Rha-Rha- $\mathrm{C}_{10}-\mathrm{C}_{10}$ relative

stationary phase in P. aeruginosa PAO1. CA effectively inhibited the expression of both las and $r h l \mathrm{QS}$ systems. Both the regulatory proteins (LasR and RhlR) and the AHL synthases (LasI and RhlI) were significantly repressed with CA. Downregulation of both these QS systems correlated with repression of their virulence-associated genes. The exact mechanism of action is unknown for these compounds. Several natural and synthetic antagonists have been described for LasR; however, the relative instability of LasR::antagonist complexes has limited biochemical characterisation in vitro. Recently, O'Reilly et al. (2018) used potent agonists rather than known antagonists to stabilise LasR in vitro. They were able to develop a focused library of agonists based on previous tri-phenyl ligands, resulting in several new LasR::agonist complexes available in/from the PDB. From these structures, O'Reilly et al. (2018) determined an important functional role for a flexible loop in the ligand binding domain b

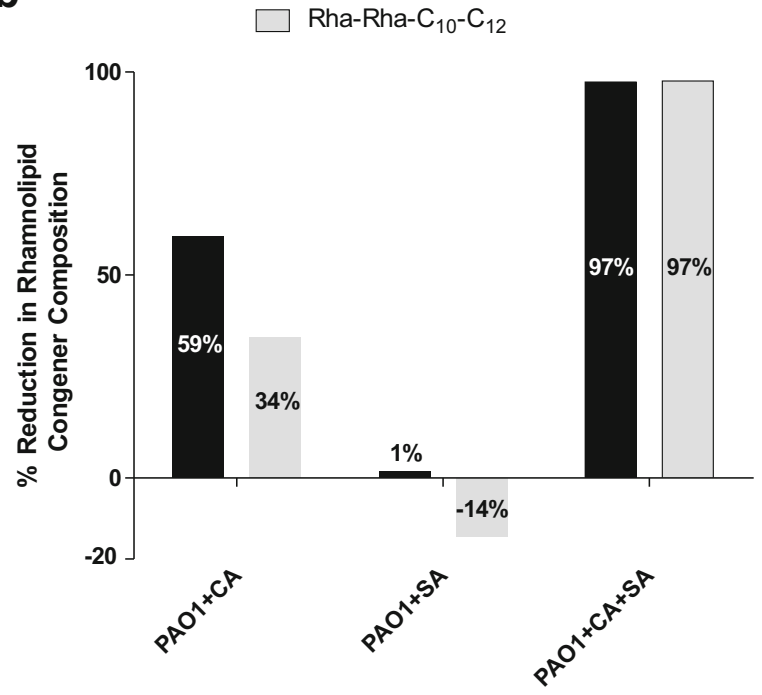

d
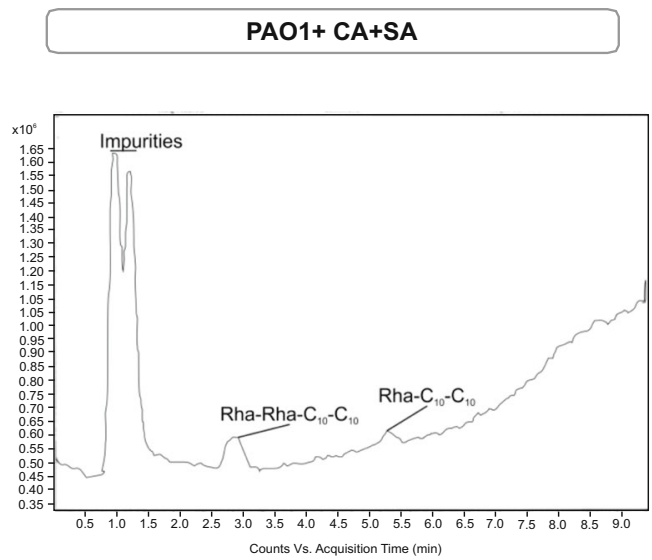

to untreated $P$. aeruginosa PAO1. RL congeners were studied by HPLCMS/MS. The HPLC chromatograms of $\mathbf{c}$ untreated $P$. aeruginosa PAO1 and $\mathbf{d} P$. aeruginosa $\mathrm{PAO} 1$ treated with trans-cinnamaldehyde (CA) and salicylic acid (SA)

(LBD), previously unknown, which upon ligand binding promotes specific conformational changes that seals the ligand binding pocket from solvent and directs the DNA binding domain (DBD) to form a transcriptional activation complex. This suggests a plausible mechanism by which agonists stabilise and antagonists destabilise LasR. These structures provide essential information for the fundamental understanding of how LuxR type receptors bind to their cognate autoinducers.

We hypothesise that CA and SA act as QS antagonists. Previously, molecular docking studies have suggested CA to interact with the LasI protein (Chang et al. 2014). LasI synthase produces 3-oxo- $\mathrm{C}_{12}-\mathrm{HSL}$ which is the ligand for LasR. RhlI is 47\% homologous with LasI (Chang et al. 2014; Gökalsin et al. 2017) and a similar mechanism of action is interpreted in AHL production. In general, LuxI synthases catalyses the transfer of an acyl group bound to acyl carrier protein (ACP) from fatty acid 
bio-synthesis to S-adenosyl-L-methionine (SAM) (Churchill and Chen 2011) which then undergoes lactonization to form the $\mathrm{N}$-acyl-homoserine lactone. $\mathrm{CA}$ is predicated to bind in the SAM binding pocket of LasI, thus preventing SAM binding and subsequent 3-oxo- $\mathrm{C}_{12}$-HSL synthesis. In the absence of AHL, LasR will not dimerize and therefore cannot bind to DNA. These interactions could modulate the QS autoinducer levels. The LasI::3-oxo- $\mathrm{C}_{12}$-HSL complex regulates the expression of many downstream genes including lasI and rhlI. Since we showed CA reduces lasI expression and previously CA has shown to reduce signal molecule concentration (Chang et al. 2014), we suggest that the intracellular concentration of autoinducer signal molecules was not sufficient to trigger the activation of genes involved with rhamnolipid and protease synthesis as shown in this study.

To date, there is no crystal structure for RhIR, its inherent instability in vitro has proven intractable to crystallisation and biochemical characterisation. Based on similarity, mechanistic interpretations of LasR with AHL ligands and inhibitors are expected to extend to RhlR. However, RhlR remains a viable QS target for developing targeted inhibitors, lasR mutants are frequently isolated from cystic fibrosis patients suggesting the redundancy of LasR as a master regulatory in chronic $\mathrm{CF}$ infections (Feltner et al. 2016).

The reductions in las $R I$ and $r h l R I$ expressions from CA treatments were correlated by assessing the activity of las-regulated elastase and protease and $r h l$-regulated pyocyanin and rhamnolipid productions. CA at sub-inhibitory concentrations caused a significant decrease in elastase $(22 \%)$ and protease (65\%) activities. Pyocyanin, which is a good indicator of rhlI inhibition (Chang et al. 2014), showed a decrease of $32 \%$ with CA. These reductions were comparable to other findings with cinnamaldehyde as QSI in the literature (Brackman et al. 2008; Brackman et al. 2011). Although CA was not able to abolish rhamnolipid production, the treatment caused a decrease in rhamnolipid yield with the two main di-rhamnolipid congeners Rha-Rha- $\mathrm{C}_{10}-\mathrm{C}_{10}$ and Rha-Rha- $\mathrm{C}_{10}-\mathrm{C}_{12}$ levels reduced by $59 \%$ and $34 \%$ respectively compared to that of untreated cells. The inhibition at post-translational levels of these virulence factors complemented the reverse transcription quantitative polymerase chain reaction (RT-qPCR) data from this study where we observed significant reductions in las $A$, lasB, $r h l A, r h l B$ and $r h l C$ expressions following CA treatment.

SA unlike CA did not produce the same level of inhibition on the transcriptional profiles of the lasRI and rhlRII genes with 2-4-fold reduction in mRNA levels being observed in the treated samples compared to untreated controls. The binding affinity of SA to the LasR protein (Yang et al. 2009) possibly promoted conformational changes in the LasR-(3-oxo- $\mathrm{C}_{12^{-}}$ HSL) complex thereby causing a reduced expression of downstream genes. Due to the QS hierarchical arrangement, rhlR expression can be regulated by las $R$; hence, the highest inhibition in QS regulatory expression with SA was seen in rhlR. This was in agreement with a previously reported study where
SA was shown to reduce rhlR expression in $P$. aeruginosa (Yang et al. 2009). The decreased expression in las QS genes consequently repressed las $A$ and las $B$ levels supporting the findings of Prithiviraj et al. (2005) using SA. Since SA did not lead to an inhibitory effect on the overall $r h l$ regulon, significant downregulation was not observed in the $r h l B$ and $r h l C$ genes. El-Mowafy et al. (2014) reported SA rich aspirin could cause significant downregulation in the lasRI and rhlRI expressions. The findings however do not fully agree with the results from this study. The study with aspirin (El-Mowafy et al. 2014) used only one reference gene, rpoD, for data normalisation along with a higher concentration of the inhibitor thereby giving slightly different results. Although SA did not show a profound effect at the transcriptional level, it seemed to be effective at the translational level. This can be hypothesised from this study considering higher reductions in virulence proteins elastase and protease were observed in the semi-quantitative assays following SA treatment. Reduction of these proteases when $P$. aeruginosa were supplemented with SA had been previously reported in a couple of studies with inhibition ranging between 40 and $80 \%$ (Prithiviraj et al. 2005; El-Mowafy et al. 2014). The choice of semiquantitative assay and the selection of growth medium were perhaps responsible for the large inhibitory range being observed within the results published in the literature (Duan and Surette 2007). The choice of media is very important as the production of secondary metabolites can be influenced by growth limiting factors present in the medium. However, SA had a negligible effect on the rhl-controlled rhamnolipid production with HPLC results being similar to the untreated sample. This complemented the qPCR findings where minimal reduction was seen in the rhamnolipid biosynthesis gene expressions. Moreover, the unavailability of the RhlR crystal structure makes it difficult to predict the possible interaction sites for these inhibitors.

\section{The combination treatment of CA and SA does not show significant inhibitory effect on QS gene expressions}

Having ascertained the potential of CA and SA to repress QSregulated gene expressions and virulence factor production when used separately, the effect of combination treatment was investigated. Even though CA and SA have different QS targets, in the form of LasI and LasR respectively, expression profiles suggested that the combination treatment was not very effective at the transcriptional level. Noticeable downregulation was observed in $r h l R$ which subsequently affected the expression of the rhamnolipid genes, further supporting the view that inhibitors targeting transcriptional regulators can be a potential drug target for reducing bacterial virulence. At post-translational level, the combination treatment was successful in reducing the rhl-regulated production of pyocyanin and rhamnolipid. The 
HPLC-MS/MS analysis showed negligible presence of rhamnolipids strengthening the idea that the effect of the combination treatment was strongly at the translational level. A computational model study of LuxI/LuxR QS suggested that LuxR competitive inhibitor, unlike LuxR non-competitive inhibitor, can display antagonistic effects when used in combination with a LuxI inhibitor (Anand et al. 2013). Therefore, if an analogy is drawn with SA targeting LasR through competitive inhibition, then some of the inhibitory potential of LuxI-type inhibitor CA can be attenuated. However, the mechanism by which this could happen is not known and was beyond the scope of current work. A better understanding on how the inhibitors bind to the target proteins will help to elucidate the lower inhibitory effects observed at expression levels with the combination treatment especially when we consider that significant downregulation was observed with $\mathrm{CA}$ alone.

With antibiotics fast losing their efficacy, alternative strategies are imperative. The sole use of QS inhibitors is unlikely to completely eradicate the bacterial infection and there would be legitimate concerns around potential toxicity of high concentrations of cinnamaldehyde where maximum permissible levels in foodstuffs have already been determined (Shreaz et al. 2016). However, since the inhibitors reduce the virulence phenotypes and weaken the bacterial biofilms, this would allow the host innate immunity and externally administered antimicrobial compounds to function more effectively. Synergistic enhancement of antibiotics by administration of sub-inhibitory quorum quenching compounds is a potentially exciting future development but little is known about such effects at the molecular level. Our system provides a suitable model system for future studies aimed at elucidating these mechanisms and should contribute to extending the useable life span of current drugs.

Funding This work was supported by Ulster University, Northern Ireland through a Vice Chancellor's Research Scholarship studentship to SAKS Ahmed.

\section{Compliance with ethical standards}

Conflict of interest The authors declare that they have no conflict of interest.

Ethical approval This article does not contain any studies with human participants or animals performed by any of the authors.

Open Access This article is distributed under the terms of the Creative Commons Attribution 4.0 International License (http:// creativecommons.org/licenses/by/4.0/), which permits unrestricted use, distribution, and reproduction in any medium, provided you give appropriate credit to the original author(s) and the source, provide a link to the Creative Commons license, and indicate if changes were made.

Publisher's note Springer Nature remains neutral with regard to jurisdictional claims in published maps and institutional affiliations.

\section{References}

Aghazadeh M, Hojabri Z, Mahdian R, Nahaei MR, Rahmati M, Hojabri T, Pirzadeh T, Pajand O (2014) Role of efflux pumps: MexAB-OprM and MexXY(-OprA), AmpC cephalosporinase and OprD porin in nonmetallo- $\beta$-lactamase producing Pseudomonas aeruginosa isolated from cystic fibrosis and burn patients. Infect Genet Evol 24:187-192

Anand R, Rai N, Thattai M (2013) Interactions among quorum sensing inhibitors. PLoS One 8:e2254

Andersen CL, Jensen JL, Ørntoft TF (2004) Normalization of real-time quantitative reverse transcription-PCR data: a model-based variance estimation approach to identify genes suited for normalization, applied to bladder and colon cancer data sets. Cancer Res 64:5245-5250

Anwar H, Costerton JW (1990) Enhanced activity of combination of tobramycin and piperacillin for eradication of sessile biofilm cells of Pseudomonas aeruginosa. Antimicrob Agents Chemother 34: 1666-1671

Bottomley MJ, Muraglia E, Bazzo R, Carfi A (2007) Molecular insights into quorum sensing in the human pathogen Pseudomonas aeruginosa from the structure of the virulence regulator LasR bound to its autoinducer. J Biol Chem 282:13592-13600

Brackman G, Defoirdt T, Miyamoto C, Bossier P, Van Calenbergh S, Nelis H, Coenye T (2008) Cinnamaldehyde and cinnamaldehyde derivatives reduce virulence in Vibrio spp. by decreasing the DNA-binding activity of the quorum sensing response regulator LuxR. BMC Microbiol 8:149-162

Brackman G, Celen S, Hillaert U, van Calenbergh S, Cos P, Maes L, Nelis HJ, Coenye T (2011) Structure-activity relationship of cinnamaldehyde analogs as inhibitors of AI-2 based quorum sensing and their effect on virulence of Vibrio spp. PLoS One 6:e16084

Brown MRW, Allison DG, Gilbert P (1988) Resistance of bacterial biofilms to antibiotics a growth-rate related effect? J Antimicrob Chemother 22:777-780

Chang CY, Krishnan T, Wang H, Chen Y, Yin WF, Chong YM, Tan LY, Chong TM, Chan KG (2014) Non-antibiotic quorum sensing inhibitors acting against $\mathrm{N}$-acyl homoserine lactone synthase as druggable target. Sci Rep 4

Chen ML, Penfold J, Thomas RK, Smyth TJP, Perfumo A, Marchant R, Banat IM, Stevenson P, Parry A, Tucker I, Grillo I (2010) Solution self-assembly and adsorption at the air-water interface of the monorhamnose and dirhamnose rhamnolipids and their mixtures. Langmuir 26:18281-18292

Chen M, Dong C, Penfold J, Thomas RK, Smyth TJP, Perfumo A, Marchant R, Banat IM, Stevenson P, Parry A, Tucker I, Grillo I (2013) Influence of calcium ions on rhamnolipid and rhamnolipid/anionic surfactant adsorption and self-assembly. Langmuir 29:3912-3923

Churchill MEA, Chen LL (2011) Structural basis of acyl-homoserine lactone-dependent signalling. Chem Reviews 111:68-85

Duan K, Surette MG (2007) Environmental regulation of Pseudomonas aeruginosa PAO1 Las and Rhl quorum-sensing systems. J Bacteriol 189:4827-4836

El-Mowafy SA, Abd El Galil KH, El-Messery SM, Shaaban MI (2014) Aspirin is an efficient inhibitor of quorum sensing, virulence and toxins in Pseudomonas aeruginosa. Microb Pathog 74:25-32

Elshikh M, Ahmed S, Funston S, Dunlop P, McGaw M, Marchant R, Banat IM (2016) Resazurin-based 96-well plate microdilution method for the determination of minimum inhibitory concentration of biosurfactants. Biotechnol Lett 38:1015-1019

Essar DW, Eberly L, Hadero A, Crawford IP (1990) Identification and characterization of genes for a second anthranilate synthase in Pseudomonas aeruginosa: interchangeability of the two anthranilate synthase and evolutionary implications. J Bacteriol 172:884-900

Feltner JB, Wolter DJ, Pope CE, Groleau MC, Smalley NE, Greenberg EP, Mayer-Hamblett N, Burns J, Deziel E, Hoffman LR, Dandekar AA (2016) LasR variant cystic fibrosis isolates reveal an adaptable 
quorum-sensing hierarchy in pseudomonas aeruginosa. MBIO 7: e01513-16

Fu W, Xie W, Zhang Z, Wang S, Wu Q, Liu Y, Zhou X, Zhou X, Zhang Y (2013) Exploring valid reference genes for quantitative real-time PCR analysis in Plutella xylostella (Lepidoptera: Plutellidae). Int J Biol Sci 9:792-802

Gellatly SL, Hancock REW (2013) Pseudomonas aeruginosa: new insights into pathogenesis and host defenses. Pathog Dis 67:159-173

Gökalsın B, Aksoydan B, Erman B, Sesal NC (2017) Reducing virulence and biofilm of Pseudomonas aeruginosa by potential quorum sensing inhibitor carotenoid: zeaxanthin. Microb Ecol 74:466-473

Gould TA, Schweizer HP, Churchill MEA (2004) Structure of the Pseudomonas aeruginosa acyl-homoserinelactone synthase LasI. Mol Microbiol 53:1135-1146

Gupta P, Chhibber S, Harjai K (2015) Efficacy of purified lactonase and ciprofloxacin in preventing systemic spread of Pseudomonas aeruginosa in murine burn wound model. Burns 41:153-162

Hentzer M, Wu H, Andersen JB, Riedel K, Rasmussen TB, Bagge N, Kumar N, Schembri MA, Song Z, Kristoffersen P, Manefield M, Costerton JW, Molin S, Eberl L, Steinberg P, Kjelleberg S, Høiby N, Givskov M (2003) Attenuation of Pseudomonas aeruginosa virulence by quorum sensing inhibitors. EMBO J 22:3803-3815

Hossain MA, Lee SJ, Park NH, Mechesso AF, Birhanu BT, Kang J, Reza MA, Suh JW, Park SC (2017) Impact of phenolic compounds in the acyl homoserine lactone-mediated quorum sensing regulatory pathways. Sci Rep 7:10618

Jayelakshmi H, Omanakuttan A, Pandurangan N, Vargis VS, Maneesh M, Nair BG, Kumar GB (2016) Clove bud oil reduces kynurenine and inhibits pqsA gene expression in P. aeruginosa. Appl Microbiol Biotechnol 100:3681-3692

Jefferson KK, Goldmann DA, Pier GB (2005) Use of confocal microscopy to analyze the rate of vancomycin penetration through Staphylococcus aureus biofilms. Antimicrob Agents Chemother 49:2467-2473

Kalia VC (2013) Quorum sensing inhibitors: an overview. Biotechnol Adv 32:224-245

Kim HS, Lee SH, Byun Y, Park HD (2015) 6-Gingerol reduces Pseudomonas aeruginosa biofilm formation and virulence via quorum sensing inhibition. Sci Rep 5

Kisch JM a, Utpatel C, Hilterhaus L, Streit WR, Liese A (2014) Pseudomonas aeruginosa biofilm growth inhibition on medical plastic materials by immobilized esterases and acylase. Chembiochem 15:1911-1919

Lee J, Zhang L (2014) The hierarchy quorum sensing network in Pseudomonas aeruginosa. Protein Cell 6:26-41

López-Causapé C, Sommer LM, Cabot G, Rubio R, Ocampo-Sosa AA, Johansen HK, Figuerola J, Cantón R, Kidd TJ, Molin S, Oliver A (2017) Evolution of the Pseudomonas aeruginosa mutational resistome in an international cystic fibrosis clone. Sci Rep 7:5555

Luna RA, Millecker LA, Webb CR, Mason SK, Whaley EM, Starke JR, Hiatt PW, Versalovic J (2013) Molecular epidemiological surveillance of multidrug-resistant Pseudomonas aeruginosa in a pediatric population of patients with cystic fibrosis and determination of risk factors for infection with the Houston-1 strain. J Clin Microbiol 51: $1237-1240$

Luo J, Dong B, Wang K, Cai S, Liu T, Cheng X, Lei D, Chen Y, Li Y, Kong J, Chen Y (2017) Baicalin inhibits biofilm formation, attenuates the quorum sensing-controlled virulence and enhances Pseudomonas aeruginosa clearance in a mouse peritoneal implant infection model. PLoS One 12:e176883

Morohoshi T, Someya N, Ikeda T (2009) Novel N-acylhomoserine lactone-degrading bacteria isolated from the leaf surface of Solanum tuberosum and their quorum-quenching properties. Biosci Biotechnol Biochem 73:2124-2127

Musthafa KS, Ravi AV, Annapoorani A, Packiavathy ISV, Pandian SK (2010) Evaluation of anti-quorum-sensing activity of edible plants and fruits through inhibition of the n-acyl-homoserine lactone system in Chromobacterium violaceum and Pseudomonas aeruginosa. Chemotherapy 56:333-339

O'Reilly MC, Dong SH, Rossi FM, Karlen KM, Kumar RS, Nair SK, Blackwell HE (2018) Structural and biochemical studies of nonnative sgonists of the lasR quorum-sensing receptor Reveal an L3 loop "Out" conformation for lasR. Cell Chem Biol 25:1128-1139

O’Toole GA (2011) Microtiter dish biofilm formation assay. J Vis Exp 47: e2437

Ouyang J, Sun F, Feng W, Sun Y, Qiu X, Xiong L, Liu Y, Chen Y (2016) Quercetin is an effective inhibitor of quorum sensing, biofilm formation and virulence factors in Pseudomonas aeruginosa. J Appl Microbiol 120:966-974

Papenfort K, Bassler BL (2016) Quorum sensing signal-response systems in Gram-negative bacteria. Nat Rev Microbiol 14:576-588

Patel SJ, Oliveira AP, Zhou JJ, Alba L, Furuya EY, Weisenberg SA, Jia H, Clock SA, Kubin CJ, Jenkins SG, Schuetz AN, Behta M, DellaLatta P, Whittier S, Rhee K, Saiman L (2014) Risk factors and outcomes of infections caused by extremely drug-resistant gramnegative bacilli in patients hospitalized in intensive care units. Am J Infect Control 42:626-631

Pfaffl MW, Tichopad A, Prgomet C, Neuvians TP (2004) Determination of stable housekeeping genes, differentially regulated target genes and sample integrity: BestKeeper - excel-based tool using pair-wise correlations. Biotechnol Lett 26:509-515

Prithiviraj B, Bais HP, Weir T, Suresh B, Najarro EH, Dayakar BV, Schweizer HP, Vivanco JM (2005) Down regulation of virulence factors of Pseudomonas aeruginosa by salicylic acid attenuates its virulence on Arabidopsis thaliana and Caenorhabditis elegans. Infect Immun 73:5319-5328

Rasmussen R (2001) Quantification on the LightCycler. In: Rapid cycle real-time PCR. p. 21-34

Scott M, Hwa T (2011) Bacterial growth laws and their applications. Curr Opin Biotechnol 22:559-565

Shreaz S, Wani WA, Behbehani JM, Raja V, Irshad M, Karched M, Ali I, Siddiqi WA, Hun LT (2016) Cinnamaldehyde and its derivatives, a novel class of antifungal agents. Fitoterapia 112:116-131

Skindersoe ME, Alhede M, Phipps R, Yang L, Jensen PO, Rasmussen TB, Bjarnsholt T, Tolker-Nielsen T, Høiby N, Givskov M (2008) Effects of antibiotics on quorum sensing in Pseudomonas aeruginosa. Antimicrob Agents Chemother 52:3648-3663

Smyth TJP, Perfumo A, Marchant R, Banat IM (2010) Isolation and analysis of low molecular weight microbial glycolipids. In: Handbook of hydrocarbon and lipid microbiology. p. 3706-3723

Sousa A, Pereira M (2014) Pseudomonas aeruginosa diversification during infection development in cystic fibrosis lungs - a review. Pathogens 3:680-703

Stover CK, Pham XQ, Erwin AL, Mizoguchi SD, Warrener P, Hickey MJ, Brinkman FSL, Hufnagle WO, Kowallk DJ, Lagrou M, Garber RL, Goltry L, Tolentino E, Westbrock-Wadman S, Yuan Y, Brody LL, Coulter SN, Folger KR, Kas A, Larbig K, Lim R, Smith K, Spencer D, Wong GKS, Wu Z, Paulsen IT, Relzer J, Saler MH, Hancock REW, Lory S, Olson MV (2000) Complete genome sequence of Pseudomonas aeruginosa $\mathrm{PAO1}$, an opportunistic pathogen. Nature 406:959-964

Valderrey AD, Pozuelo MJ, Jimenez PA, Macia MD, Oliver A, Rotger R (2010) Chronic colonization by Pseudomonas aeruginosa of patients with obstructive lung diseases: cystic fibrosis, bronchiectasis, and chronic obstructive pulmonary disease. Diagn Microbiol Infect Dis 68:20-27

Vandesompele J, De Preter K, ilip P, Poppe B, Van Roy N, De Paepe A, rank S (2002) Accurate normalization of real-time quantitative RTPCR data by geometric averaging of multiple internal control genes. Genome Biol 3:34-31

Wagner VE, Bushnell D, Passador L, Brooks AI, Iglewski BH (2003) Microarray analysis of Pseudomonas aeruginosa quorum sensing 
regulons: effects of growth phase and environment. J Bacteriol 185: 2080-2095

Werner E, Roe F, Bugnicourt A, Franklin MJ, Heydorn A, Molin S, Pitts B, Stewart PS (2004) Stratified growth in Pseudomonas aeruginosa biofilms. Appl Environ Microbiol 70:6188-6196

Wu H, Song Z, Hentzer M, Andersen JB, Molin S, Givskov M, Høiby N (2004) Synthetic furanones inhibit quorum-sensing and enhance bacterial clearance in Pseudomonas aeruginosa lung infection in mice. J Antimicrob Chemother 53:1054-1061
Yang L, Rybtke MT, Jakobsen TH, Hentzer M, Bjarnsholt T, Givskov M, Tolker-Nielsen T (2009) Computer-aided identification of recognized drugs as Pseudomonas aeruginosa quorum-sensing inhibitors. Antimicrob Agents Chemother 53:2432-2443

Zhang Y, Miller RM (1992) Enhanced octadecane dispersion and biodegradation by a Pseudomonas rhamnolipid surfactant (biosurfactant). Appl Environ Microbiol 58:3276-3282 